\title{
O smartphone na aprendizagem à luz da Teoria Histórico Crítica
}

NETO CUNHA, Joaquim Ferreira da ${ }^{1}$

\section{RESUMO}

Este trabalho tem por objetivo principal refletir a utilização das tecnologias móveis na aprendizagem à luz da Teoria Histórico Critica. A metodologia a ser utilizada é a revisão literária em textos consagrados da literatura da área pesquisada. O smartphone, enquanto tecnologia digital móvel alterou a forma de comunicação e informação, convergindo diversas funcionalidades com o fato de se fazer onipresente, e apresentando inúmeras possibilidades que podem ser utilizadas a favor do ensino-aprendizagem. Nesse sentido, a Teoria Histórico Critica vem contribuir com o processo ensino e aprendizagem, pois propicia ao educando uma aprendizagem significativa, promovendo suas capacidades psíquicas, a socialização do saber sistematizado, promovendo a promoção humana, alterando seus comportamentos para se colocarem conscientemente no âmbito social. Destarte, percebemos que a tecnologia móvel smartphone é uma auxiliar muito importante no processo de ensino, onde os educando buscam constantemente novos conhecimentos.

Smartphone. Tecnologias da Informação e Comunicação (TIC). Teoria Histórico Crítica.

\section{Smartphone in the learning process through Critical Historical Theory}

\begin{abstract}
This work has as main objective to reflect the use of mobile technologies in learning in the light of the Critical Historical Theory. The methodology to be used is the literary revision of consecrated texts of the literature of the researched area. The smartphone, as a mobile digital technology, changed the form of communication and information, converging several functionalities with the fact of being ubiquitous, and presenting numerous possibilities that can be used in favor of teaching-learning. In this sense, the Critical Historical Theory contributes to the teaching and learning process, as it provides the student with meaningful learning, promoting their psychic abilities, the socialization of systematized knowledge, promoting human promotion, changing their behaviors to place themselves consciously in the social sphere. Thus, we realize that mobile smartphone technology is a very important aid in the teaching process, where the students constantly seek new knowledge.
\end{abstract}

\footnotetext{
${ }^{1}$ Mestrando em Educação pela FCT-UNESP. Professor da EMEFEI, Armênio Macário Ribeiro, Brasil. E-mail: neto55neto55@hotmail.com. Lattes: http://lattes.cnpq.br/9732689973876161. Orcid: https://orcid.org/0000-0002-4254-6904.
} 
Smartphone. Information and Communication Technologies (TIC). Critical Historical Theory.

\section{El Smartphone en el Aprendizaje a la Luz de la Teoría Histórica Crítica}

\section{RESUMEN}

Este trabajo tiene como objetivo principal reflejar acerca del uso de tecnologías móviles en el aprendizaje a la luz de la Teoría Histórica Crítica. La metodología a utilizar es la revisión literaria de textos consagrados de la literatura del área investigada. El smartphone, como tecnología digital móvil, ha cambiado la forma de comunicación e información, convergiendo varias características con el hecho de que es omnipresente y presenta numerosas posibilidades que pueden utilizarse a favor de la enseñanza-aprendizaje. En este sentido, la Teoría Histórica Crítica viene a contribuir al proceso de enseñanza y aprendizaje, ya que proporciona al estudiante un aprendizaje significativo, promueve sus habilidades psíquicas, socializa el conocimiento sistematizado, promueve la promoción humana, cambia sus comportamientos para ubicarse conscientemente en la esfera social. Por lo tanto, nos damos cuenta de que la tecnología móvil smartphone es una ayuda muy importante en el proceso de enseñanza, donde los estudiantes buscan constantemente nuevos conocimientos.

Smartphone. Tecnologías de la Información y la Comunicación (TIC). Teoría Histórica Crítica.

\section{Lo smartphone nell'apprendimento alla luce della teoria storica critica}

\section{RIASSUNTO}

Questo lavoro ha come obiettivo principale quello di riflettere l'uso delle tecnologie mobili nell'apprendimento alla luce della teoria storica critica. La metodologia da utilizzare è la revisione letteraria in rinomati testi della letteratura dell'area ricercata. Lo smartphone, in quanto tecnologia digitale mobile, ha cambiato la forma di comunicazione e informazione, facendo convergere diverse funzionalità con il fatto che è onnipresente e presenta numerose possibilità che possono essere utilizzate a favore dell'insegnamento-apprendimento. In questo senso, la Teoria storica critica arriva a contribuire al processo di insegnamento e apprendimento, poiché fornisce allo studente un apprendimento significativo, promuovendo le sue capacità psichiche, la socializzazione della conoscenza sistematizzata, promuovendo la promozione umana, cambiando i loro comportamenti per posizionarsi consapevolmente nella sfera sociale. Pertanto, ci rendiamo conto che la tecnologia dello smartphone mobile è un aiuto molto importante nel processo di insegnamento, in cui gli studenti cercano costantemente nuove conoscenze.

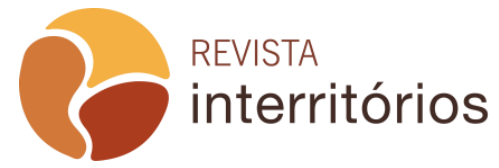


Smartphone. Tecnologie dell'informazione e della Comunicazione (TIC). Teoria Storica Critica.

\section{INTRODUÇÃO}

A sociedade moderna vivencia a era da conexão, da informação ultra veloz, da mobilidade e a onipresença da comunicação humana por meio dos aparatos tecnológicos, desencadeando novas formas de interação e comunicação em ambientes "online". Nesse sentido, há uma vertente do uso cada vez mais crescente e acelerado de aparelhos móveis, como o celular, o smartphone, o tablet, IPhone, IPad, entre outros, que com a mobilidade e o fácil acesso às informações em qualquer lugar, com alcance amplo a qualquer hora, se conectando de forma fácil e rápida a outros dispositivos móveis, localizando pessoas, produtos e serviços personalizados, impulsionaram essa tecnologia móvel a estruturar e crescer rapidamente para se adaptar as necessidades dos usuários.

No entanto, essa situação transformou-se de forma radical com a propagação dos celulares, principalmente com a introdução no mercado do IPhone, em 2007, da Empresa Apple. Após essa revolução tecnológica, o celular não mais se limitou a ser um aparelho telefônico, mas sim, passou a ser considerado um computador de bolso com variadas funções e aplicabilidades pelo acesso à internet (ZUIN \& ZUIN, 2018).

Diante desse cenário, é inevitável que essas mídias apareçam na escola, pois o smartphone, enquanto um "computador de bolso", desde cedo se faz presente no cotidiano das crianças e intrinsecamente no dos pais e responsáveis, seja como forma de entretenimento ou "babá" (disciplinador) (SILVA, 2013). E a escola, enquanto espaço de construção do conhecimento, necessita saber e compreender com quais fins os alunos utilizam essas mídias móveis e como potencializar esses aparatos tecnológicos como ferramentas de aprendizagem.

Türcke (2010) afirma que é necessário o uso das tecnologias na educação com a perspectiva de modificar a forma de ensino e aprendizagem, deixando de formar meramente consumidores de informações, mas passando a formar produtores de cultura e conhecimentos essenciais a formação humana.

Todavia, esta nova linguagem tecnológica da qual a criança está inserida e articulada, deve ser bem vista e aceita pelo professor, pois sua utilização, mediada, intervinda e intencionada pelo docente, pode conduzir o processo de ensino na direção de melhorias e avanços, como uma ferramenta que conduz e cria estratégias de ensino-aprendizagem, por meio de um letramento digital. 
Este artigo tem como tema $\mathrm{O}$ uso das tecnologias moveis na aprendizagem à luz da Teoria Histórico Critica. Assim, o intuito do presente trabalho é promover uma reflexão do uso das tecnologias móveis na aprendizagem à luz da Teoria Histórico Critica. A metodologia a ser utilizada é a Revisão Sistemática da literatura, enquanto fundamentação teórica, em textos consagrados da literatura da área pesquisada, pois compreende como uma forma de aprofundar o conhecimento, por meio da análise e reconstrução de teorias, realidades, leis e discussões, identificando a influência dos meios tecnológicos e os reflexos que o smartphone, enquanto mídia móvel traz a criança.

Neste contexto, a presente temática aqui levantada se faz pertinente na medida em que se propõe a não permitir que a tecnologia torne-se um objeto estranho para o professor, que se vê rodeado e acostumado a currículos enlatados, grades curriculares, ao conservadorismo tecnológico, e à ordem explicadora dos conhecimentos (RANCIÈRE, 2004).

\section{As TIC's na educação}

Acessar a internet, fazer ligações, usar as redes sociais, checar e-mails, falar ao telefone, assistir televisão, enviar mensagens para pessoas do outro lado do país ou até mesmo do planeta, são atividades que nem sempre fizeram parte do cotidiano ou mesmo imaginariam existir nossos antepassados. Entretanto, atualmente nos adaptamos a essa sociedade vista tecnológica, no qual a velocidade da informação é cada vez intrínseca e universal.

Vivenciamos em nossos dias uma grande transformação e revolução na forma de comunicação e como processo de transmissão e processamento. Levy (1999) refere-se a essas mudanças devido a um impacto das novas tecnologias da informação e comunicação sobre a sociedade e a cultura, (res) significando os novos hábitos dos indivíduos do mundo. Essas transformações tecnológicas devem ao rompimento das barreiras econômicas, culturais e sociais, na rápida e espantosa globalização.

Esse fenômeno da globalização está permitindo acesso, seja real ou virtual, a todo tipo de informação e comunicação das camadas da sociedade. Kenski (2012) afirma que as chamadas Tecnologias da Informação e Comunicação são o resultado da fusão de três vertentes técnicas: a informática, as telecomunicações e a eletrônica, criando um "encantamento no meio educacional à medida que se descortinou um mundo de novas possibilidades, principalmente em relação aos conceitos de espaço e distância".

As tecnologias de informação e comunicação (TIC's) exercem um papel cada vez mais importante na forma de nos comunicarmos, aprendermos e vivermos. As Tecnologias da Informação e Comunicação referidas como TIC's 
são consideradas como sinônimo das tecnologias da informação (TI). Contudo, é um termo geral que frisa o papel da comunicação na moderna tecnologia da informação.

Kenski (2012) define as TIC's como o "processo de produção e uso dos meios baseados no uso da linguagem oral, da escrita e da síntese entre som, imagem e movimento, como vídeo, televisão, computador e telefones celulares". Tais tecnologias possuem suas próprias lógicas, linguagens e maneiras particulares de comunicar-se, evoluem com muita rapidez e estão em permanente mudança, modificando as formas de ensinar e aprender, possibilitando o protagonismo do aluno no processo de construção de conhecimento, e melhorando a qualidade da aprendizagem.

Os alunos transformaram-se radicalmente com a globalização e a "super" evolução das TIC's, significando que não são os mesmos para os quais o sistema educacional foi criado e que essa nova produção de conhecimento, no encurtamento do tempo e do espaço, gera uma nova transmissão de informações e produção do conhecimento (PRENSKY, 2011).

Para Moran (2012), as TICs permitem melhoria da qualidade na educação, mas não de forma pragmática, mas sim qual função dos professores nessa educação contemporânea e a mudança de antigos modelos de aprendizagem: da transmissão e reprodução para a construção de conhecimento. Pensando, não se podem inserir as TICs no processo educacional sem a mínima intenção e respeito às especificidades do ensino e da própria tecnologia para garantir o seu bom uso e (re) pensar metodologias para utilizar esses equipamentos no processo de ensino e aprendizagem.

Das tecnologias da informação e comunicação presentes na vida do sujeito, a internet e o smartphone são os que mais se disseminam e consequentemente, os mais utilizados. Esse novo comportamento humano redefinido por uma infinidade de informações, altera a sociedade como um todo, pois a comunicação passa a assumir um espaço ainda mais privilegiado na vida social. Novas visões de mundo determinam a formação de uma nova sociedade, integralizada pela tecnologia (MORAN, 2012).

\section{O smartphone enquanto Tecnologia Móvel}

Celulares são verdadeiros computadores portáteis interligados na internet, com inúmeros recursos internos, capazes de filmar, tirar fotos, produzir montagens, gravar o áudio que o usuário desejar, além de oferecer uma grande variedade de acesso aos aplicativos, programas criados por pessoas jurídicas para atender necessidades de todo tipo, inclusive, educativas (LOPES, PIMENTA, 2017). 
O smartphone enquanto tecnologia móvel tem impulsionado e massificado o acesso à tecnologia devido ao seu baixo custo e acessibilidade a pessoas pertencentes às classes de baixa renda (CETIC. BR, 2018).

A convergência midiática promove na educação a ampliação e diversificação dos processos de comunicação e interação; produção e disseminação de informações e conhecimentos; acesso a conteúdos digitais em qualquer lugar e horário, eliminando limites de tempo e espaço; e, principalmente, diferentes.

No contexto brasileiro, além de ser o dispositivo mais difundido, o telefone celular é, em muitos casos, a única opção de acesso à Internet para população, estando presente em áreas em que há maior dificuldade de acesso à banda larga fixa e a outros dispositivos. Isso ocorre, sobretudo, entre a população economicamente menos favorecida e que vive em áreas rurais, a qual dispõe de menor diversidade de alternativas de conectividade. Esse cenário representa, por um lado, a inserção de parcela da população no mundo on-line. No entanto, o uso exclusivo do telefone celular impacta as atividades realizadas e, consequentemente, o potencial desenvolvimento de habilidades múltiplas por crianças e adolescentes (CETIC. BR, 2017).

A UNESCO (Organização das Nações Unidas para a Educação, a Ciência e a Cultura) em suas Diretrizes de políticas da UNESCO para a aprendizagem móvel (2013) opta por adotar uma definição ampla para os smartphones, enquanto aparelhos móveis, reconhecendo simplesmente que são digitais, facilmente portáteis, de propriedade e controle de um indivíduo e não de uma instituição, com capacidade de acesso à internet e aspectos multimídia, e podem facilitar um grande número de tarefas, particularmente aquelas relacionadas à comunicação.

Difícil encontrar uma pessoa que não tenha um aparelho ou uma criança que não teve ou tem contato com o aparato, demonstrando como essa tecnologia está permeada na sociedade. O smartphone acaba se tornando uma extensão do corpo humano, visto que guardar números, datas, eventos, entre outros fatores, não se faz mais importante, pois esse aparato guarda mais informações com quantidade e qualidade do que a própria anatomia do corpo, funcionando como uma reserva do componente cerebral, confiando plenos poderes e armazenando a totalidade de quem somos (MACHADO, 2014).

Acredita-se que a criação de novos espaços voltados para as práticas educacionais mediadas pelas linguagens das tecnologias móveis favorece a elevação dos níveis de educação do Brasil. Pelo seu caráter portátil, tais tecnologias propiciam atividades, que podem envolver professores e alunos e demais atores educativos que podem interagir na busca de novas aprendizagens e conhecimentos (ZUIN \& ZUIN, 2018). 
Dessa maneira, os smartphones são aparelhos que fazem parte deste grupo das tecnologias digitais da informação e comunicação, possuindo ferramentas que podem auxiliar no processo de ensino-aprendizagem, permitindo e promovendo uma a interatividade entre aluno, conhecimento e com o professor, contribuindo para se ter uma sociedade conectada, colaborativa, responsável e crítica.

Professor e aluno tornam-se parceiros nesta incessante busca do aprender, pois as novas tecnologias da informação se relacionam diretamente com a ideia de emancipação humana, do desenvolvimento da criatividade, da autocritica, da autonomia e da liberdade responsável (ALMEIDA \&PRADO, 1999).

\section{O smartphone à luz da Teoria Histórico Critica}

Segundo Duarte (2003), Vygotsky foi uns dos grandes estudiosos que desenvolveu a Teoria Histórico-Cultural a partir dos pressupostos de Marx, onde - desenvolvimento do ser humano está condicionado às interações estabelecidas no meio social, ou seja, para que um sujeito se desenvolva se faz necessário que ele aproprie da cultura material e intelectual produzida historicamente pela humanidade. Essa apropriação depende da forma como o sujeito em desenvolvimento estabelece com o ser mais desenvolvido, da transmissão de signos, símbolos, culturas e relações sociais que ampliem a linguagem e o pensamento humano.

Na sociedade moderna, o homem divide espaço com as máquinas, e as relações constituídas por ambos se tornam cada vez mais inseparáveis. Em cada atividade do cotidiano, como em casa, no trabalho, na escola, nos parques, em diversos espaços e ambientes sociais, a tecnologia possui seu lugar de utilidade, sendo, muitas vezes, uma necessidade e realidade. Permeia em nossa mente, uma impossibilidade de imaginar a sobrevivência do homem sem a tecnologia atualmente.

O modo frenético como crianças, jovem e adulto consomem tecnologias e mídias nesse modelo de sociedade atual, comprova que a era digital revolucionou e revoluciona o comportamento, os sentimentos, a educação, 0 modo de viver, ser e pensar dos indivíduos (SILVA, 2013).

Saber utilizar essas tecnologias móveis com foco no ensino e aprendizagem, em particular o smartphone, é uma necessidade fundamental para o desenvolvimento pedagógico efetivo, para que o estudante consiga avançar de nível de conhecimento real para um nível de conhecimento potencial de aprendizagem. Dessa maneira, a tecnologia integrada é importante no ambiente escolar, fazendo significado ao educando, pois é uma prática social que vivencia no cotidiano. Mas para a reflexão teórica ser integrada dentro da 
sala de aula, se faz necessário que professores e alunos tenham uma apropriação crítica dos conteúdos escolares para transformar a vida do estudante e da sociedade em sua totalidade (GASPARIN, 2012).

Para a Psicologia Histórico-cultural, o método dialético trata das leis mais gerais do desenvolvimento da natureza, da sociedade e do pensamento humano, assim, tendo em vista a complexidade humana, acredita-se que a aplicação desse instrumental metodológico na escola possibilitará aos educadores a apreensão dos fenômenos humanos e sociais na sua concretude, ou seja, na sua verdadeira forma de existir e se manifestar (VIOTTO FILHO, 2007).

Assim, pensemos o smartphone, enquanto objeto cultural simbólico, como um instrumento metodológico, no qual possibilita o educador compreender seus alunos, reconhecendo-os como síntese de múltiplas determinações biológicas, históricas e sociais, superando as visões naturalizantes e positivistas sobre a criança, mas de forma concreta (VIOTTO FILHO, 2007).

Viotto Filho (2007) apud Vygotsky (1996) afirma que a dialética é fundamental, seja pra explicitar e apresentar a interdependências entre os fenômenos naturais, humanos e sociais e que a fonte de desenvolvimento humano funda-se na unidade e luta de contrários, ou seja, cada fase na história gera sua fase contrária e precisa ser compreendido na escola, dada a complexidade de relações que lá são estabelecidas e que estão diretamente relacionadas com o desenvolvimento dos educandos.

Vygotsky (1996) defende que a psicologia precisa desvelar, ir além da aparência externa dos fenômenos, sua origem e natureza, mas ir atrás da verdadeira relação dessa manifestação externa, analisando os processos e descobrindo como o smartphone se manifesta verdadeiramente na escola, para que o educador possa compreender o sujeito humano numa perspectiva de totalidade, mas que de modo algum queira oferecer a solução definitiva, a verdade absoluta para a questão do desenvolvimento humano na escola.

O Ser humano vai se tornando cada vez mais humano à medida que vai se apropriando dos objetos (materiais e simbólicos) construídos pela humanidade e torna esses objetos "órgãos de sua individualidade" (OLIVEIRA, 1996). Ainda, esse ser humano constrói coletivamente seu desenvolvimento na Atividade Social, pois à medida que se apropria do mundo natural, social, tecnológico e histórico, seus pensamentos, linguagem, consciência, sentimentos e comportamentos moldam esse desenvolvimento humano.

Neste sentido, o ponto de partida para a aprendizagem e a apropriação de conteúdos de forma completa, é a realidade social ampla, tornando e compreendendo o professor e o aluno como agentes sociais, e a aprendizagem como prática social, como forma de solucionar algum problema dessa prática social, onde os estudantes se apropriam do conhecimento e conseguem 
sintetizá-los, mas de forma diferenciada, em outro nível de conhecimento. (GASPARIN, 2012).

Vygotsky (1990) aponta para atividade criadora do homem, aquela em que se cria algo novo, como a criação de imagens e ações que pertencem a esse quadro criador ou combinatório., combinando elementos da experiência anterior, erigindo novas situações e novos comportamentos. A imaginação é a base de toda essa atividade criadora, manifestando-se em campos da vida cultural, cientifica e técnica. Tudo que nos cerca (mundo da cultura) foi feita pelas mãos humanas, produto da imaginação e da criação humana que nela baseia.

Nesse sentido, conforme Vygotsky (1990), a tecnologia móvel smartphone pode ser considerada uma atividade criadora, pois enquanto uma invenção tem por elementos tomados pela realidade e cristalizados como fato de experiência da pessoa a qual criou esse objeto.

O smartphone propicia a criança, ao contato com inúmeras informações, uma riqueza de experiências, quanto mais viu, ouviu e vivenciou, mais ela sabe e assimilou, mais produtiva e significativa será sua imaginação. A imaginação é uma condição totalmente necessária à atividade mental humana, servindo a nossa experiência, onde precisa ser completada, realizada num artefato, tomando uma forma, como o smartphone, para integrar, de maneira objetiva a produção coletiva. (VYGOTSKY, 2009).

Leontiev (1978) aponta que é no encontro do aluno com os objetos culturais, que pode ser o objeto "smartphone", que mesmo não proporcionado pela escola, mas sim decorrente dos educando que lá se encontram, e dependendo da interação e mediação que esse professor fará a partir desse objeto, o sujeito encontrará os motivos sociais das suas necessidades e, colocarse-á em ação, em atividade. Entende-se que o educando, não pode ser visto como um mero objeto que precisa adaptar-se às condições da escola e da sociedade; "ele deve ser reconhecido a partir de sua atividade, nas relações que estabelece com os bens simbólicos e materiais que the são possibilitados, desenvolvendo-se e satisfazendo suas necessidades nesse processo" assumindo assim a posição de sujeito no processo de aprendizagem e apropriação da cultura, como produto e produtor de sua história e da história da sociedade da qual faz parte (VIOTTO FILHO, 2007).

Baumam (2001) define o dispositivo móvel (smartphone) como o objeto cultural da era da instantaneidade, permitindo aos sujeitos, estar em contato uns com os outros, por meio de chamadas telefônicas, mensagens de texto, câmera, música, aplicativos, jogos digitais e internet. Há de alguma forma uma imanência de um sistema cultural no uso dos dispositivos tecnológicos, com a "convergência de vários sistemas de signos operando de uma forma não prevista que, em algum momento, se estabelece por conta de suas práticas de consumo" que vão muito além da posse de bens, originando novos modos de ser e de viver 
que interagem com a construção de subjetividades, afinal os objetos consumidos são cultura e, no processo de consumo e uso, se constroem novos significados.

Nessa perspectiva, a apropriação dos objetos culturais, principalmente a linguagem, apresenta-se como fundamental para se compreender os sujeitos sociais em processo de desenvolvimento. No processo de comunicação, mediado por signos, como o Smartphone, as funções psicológicas superiores passam por uma etapa externa de desenvolvimento, para depois se tornar função específica e interna do sujeito, pois, toda função psíquica superior foi externa por ter sido social antes que interna; a função psíquica [de um indivíduo] propriamente dita era antes uma relação social de duas pessoas [do indivíduo com o outro]. O meio de influência sobre si mesmo é inicialmente o meio de influência sobre os outros [...] o meio de influência dos outros é o meio de influência sobre o indivíduo (VIGOTSKY, 1990).

O processo de aprendizagem se dá desde já, pois é na aprendizagem que possibilita a criança se desenvolver na orientação, na interação com outro. A escola deve criar necessidades para a atividade de estudo, de leitura de escrita e de amor (ou ódio) ao conhecimento (VYGOTSKY, 2009). Dessa forma, precisamos criar condições reais do objeto, bem como o Smartphone, para os alunos aprenderem, fazendo-os avançarem ao desenvolvimento, saindo do nível atual do conhecimento (atividade autônoma) e passando-os ao Nível de Zona de Desenvolvimento Potencial, construída na escola, as quais são imprescindíveis para que o sujeito possa desenvolver um tipo de consciência diferenciada e crítica, que avance à consciência de senso comum, normalmente desenvolvida na vida cotidiana, fora da escola.

Assim, na tentativa de compreender a importância da apropriação dos elementos históricos e culturais construídos pela humanidade, como fundamentais no processo de desenvolvimento e humanização dos sujeitos, passa a ser fundamental considerar a relação entre aprendizagem e desenvolvimento, como tal apropriação, se significativa, possibilitará aos profissionais da educação, instrumentos teóricos e metodológicos fundamentais para se rever o currículo, as disciplinas, a avaliação, carga-horária, conteúdos, material didático-pedagógico, estratégias de ensino, processos de aprendizagem, "dentre outras questões, próprias da educação e da escola, diretamente relacionadas ao processo de desenvolvimento e humanização dos sujeitos" (VIOTTO FILHO, 2005, p. 27).

Logo, a relação entre processo de desenvolvimento e aprendizagem, poderá possibilitar aos educadores condições diferenciadas para se compreender os estudantes, possibilitando uma visão mais ampla e dinâmica do processo de desenvolvimento desses sujeitos, com vistas à construção de intervenções educativas mais coerentes com realidade histórica e social e, portanto, coerente com as necessidades concretas dos alunos presentes na 
escola, levando-os a consciência crítica e tal qual a humanização atingir este sujeito em sua plenitude.

\section{Considerações Finais}

Em se tratando de informação e comunicação, as diversas possibilidades tecnológicas surgiram como uma alternativa da era moderna, facilitando os modos da educação com a inserção dos computadores nas escolas, aprimorando e permitindo o uso da tecnologia pelos alunos, visto que o acesso a informações e a realização de diversas tarefas inerentes à vida humana, além de qualificar os professores por meio da criação de redes e comunidades virtuais.

Desta maneira, as Tecnologias Digitais constroem e reconstroem todo ato do ser humano, influenciando até mesmo a sua forma de construção da identidade (MARQUES, 1999). Fonseca apud Straubhaar e LaRose (2013) diz que a infraestrutura de telecomunicação combinada com tecnologias de computação pode ser considerada o sistema nervoso central da comunicação contemporânea, denominada "Smartphone".

As tecnologias digitais móveis, por serem altamente portáteis e relativamente baratas, ampliaram enormemente o potencial e a viabilidade da aprendizagem personalizada. Além disso, à medida que aumentam à quantidade e a diversidade de informações que os aparelhos móveis podem coletar sobre seus usuários, a tecnologia móvel torna-se capaz de melhor individualizar a aprendizagem. Os smartphones, nos diversos aparelhos nos bolsos de milhões de pessoas, podem oferecer aos estudantes maior flexibilidade para avançar em seu próprio ritmo e seguir seus próprios interesses, aumentando potencialmente sua motivação para buscar oportunidades de aprendizagem (UNESCO, 2013).

Nesse sentido, a escola enquanto instituição cultural e promovedora de ações sociais, culturais e históricas, deve criar necessidades reais de aprendizagem, como: estudar, ler, escrever, e potencialmente ir além do conhecimento superficial, mas incorporando aquisições da humanidade, desenvolvendo uma consciência crítica dos sujeitos que ali convivem, não apenas repetindo aquilo que é considerado importante por uma parte da sociedade, mas torna-la melhor, estabelecendo um diálogo entre cultura e educação (LEONTIEV, 1978).

O sujeito se apropria desse objeto, por meio do instrumento simbólico smartphone, e através da mediação de outro sujeito, no caso o professor com o aluno, provoca transformações, modifica o comportamento e o desenvolvimento humano, resultando em aprendizagem por meio de objetos culturais. Infelizmente nossa educação por não atender essa sistematização de relações entre o sujeito e os objetos culturais, resulta que nem todos se apropriem do

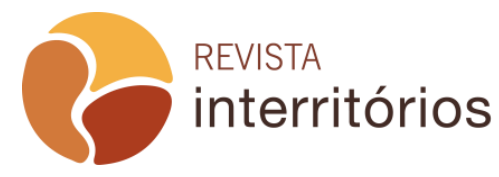


mesmo nível esperado dos fenômenos culturais, difundindo uma única visão como integradora de humanização, visto que a criança por meio da comunicação e da relação com outros homens aprende por meio de aptidões (LEONTIEV, 1978).

A escola por sua vez, enquanto instituição social deve criar esse espaço de relação orgânica, essência e estável à relação do educando durante o período de escolarização, transformando-os em verdadeiramente comunidade, os desenvolvendo de forma livre, consciente, democrática, de forma que sua relação não seja obrigatória, acidental ou até mesmo forçada (VIOTTO FILHO, 2014).

Logo, cabe à educação avaliar as práticas culturais desenvolvidas, bem como os educadores resguardarem os valores que possibilitam o desenvolvimento humano, um sistema de educação que lute pela ideologia, ampliando e promovendo um desenvolvimento intelectual e multilateral, com criticidade, promovendo projetos educacionais que superem as relações preconceituosas e saibam valorizar os conhecimentos provenientes das diferentes culturas existentes, de forma a tornar os indivíduos atores sociais, protagonistas da própria história e cidadãos emancipados, em uma escola justa, igualitária e acima de tudo DEMOCRÁTICA sobre todas as manifestações da sociedade.

\section{REFERÊNCIAS}

ALMEIDA, Maria E. B. \& PRADO, Maria E. B. B. Um retrato da informática em educação no Brasil. 1999. In: http://www.proinfo.gov.br. Acesso em: 12 de agosto de 2019.

BAUMAN, Zygmunt. Modernidade Líquida. Rio de Janeiro: Jorge Zahar, 2001.

CETIC.BR. Pesquisa Sobre o Uso das Tecnologias de Informação e Comunicação nos Equipamentos Culturais Brasileiros 2018. Disponível em: < https://www.cgi.br/media/docs/publicacoes/1/tic_cultura_2018_livro_eletronico.pdf >. Acesso em 28 de agosto de 2019.

CETIC.BR. Pesquisa Sobre o Uso das Tecnologias de Informação e Comunicação nas Escolas Brasileiras Educação 2017. Disponível em: <https://www.cgi.br/media/docs/publicacoes/2/tic_edu_2017_livro_eletronico.pdf.> . Acesso em 28 de agosto de 2019.

DUARTE, N. A individualidade para-si: contribuição a uma teoria histórico-social da formação do indivíduo. Campinas, Autores Associados, 1993.

FONSECA, Ana Graciela M. F. da. Aprendizagem, mobilidade e convergência: Mobile Learning com Celulares e Smartphones. Rev. Elet. do Prog. de PósGraduação em Mídia e Cotidiano, n.2, p. 256 - 283, jun. 2013. Disponível em: <http://www.ppgmidiaecotidiano.uff.br/ojs/index.php/Midecot/article/viewFile/42/4 
8>. Acesso em: 21 agosto 2019.

GASPARIN, J. L. Uma didática para a pedagogia histórico-crítica. 5. Ed. Campinas, SP: Autores Associados, 2012.

KENSKI, Vani Moreira. Educação e tecnologias: Um novo ritmo da informação.8. ed. Campinas: Papirus, 2012. p. 15-25.

LEONTIEV, A. N. O desenvolvimento do psiquismo. Lisboa: Livros Horizonte, 1978.

LÉVY, P. Cibercultura. 2. ed. São Paulo: Editora 34, 2000.

LOPES, Priscila Almeida; PIMENTA, Cintia Cerqueira Cunha. O uso do celular em sala de aula como ferramenta pedagógica: Benefícios e desafios. Revista Cadernos de Estudos e Pesquisa na Educação Básica, Recife, v.3, n.1, p.52-66, 2017. CAP UFPE.

MACHADO, Helena. Tecnologias que incriminam. Olhares de reclusos na era do CSI. Coimbra: CES/Almedina, 288 p. 2014.

MORAN, José. Novas tecnologias e mediações pedagógicas. Campinas, SP. Papirus, 2012.

OLIVEIRA, B. O trabalho educativo: reflexões sobre paradigmas e problemas do pensamento pedagógico brasileiro. Campinas: Autores Associados, 1996.

PRENSKY, M. From digital nativesto digital wisdom: hopefulessays for $21 \mathrm{st}$ Century learning. Thousand Oaks: Corwin, 2011.

RANCIÈRE, Jacques. Aux bords du politique. Paris: Gallimard, 2004.

SILVA, Delcio B. As principais tendências pedagógicas na prática escolar brasileira e seus pressupostos de aprendizagem. Disponível em:

http://www.ufsm.br/lec/01_00/DelcioL\&C3.htm, Acesso em: 14 de setembro de 2019.

TÜRCKE, C. Sociedade excitada: filosofia da sensação. Campinas: Editora da Unicamp, 2010.

UNESCO. Policy Guidelines for Mobile Learning, publicado em 2013 pela Organização das Nações Unidas para a Educação, a Ciência e a Cultura (UNESCO), 7, place de Fontenoy, 75352 Paris 07 SP, France.

VIOTTO FILHO, I. A. Psicologia Escolar e Psicologia Social-Comunitária: diálogos para a construção de uma perspectiva crítica de atuação do psicólogo na escola. Tese (Doutorado em Educação/Psicologia da Educação) - Programa de Psicologia da Educação, PUC/SP, São Paulo, 2005.

VIOTTO FILHO, I A. Psicologia Histórico-cultural: algumas contribuições para a ação do educador numa escola em transformação. Revista Educere et educare, v.I, 2007, UNIOESTE/PR.

VIOTTO FILHO, I.A. Pensando a escola pública como comunidade: contribuições teórico-críticas da filosofia de agnes heller. In: Stela Miller; Maria Valéria Barbosa; 
Sueli Guadelupe de Lima Mendonça. (Org.). Educação e Humanização: as perspectivas da teoria histórico-cultural. 1ed. Jundiai: Paco Editorial, 2014, v.1, p. 7244.

VYGOTSY, L.S. La imaginacion y el arte em la infância (ensayo psicológico). Madrid: Akal, 1990.

VYGOTSKY, L.S. Teoria e Método em Psicologia. S. Paulo: M. Fontes, 1996.

VYGOTSKY, Lev S. Imaginação e criação na infância: ensaio psicológico: livro para professores/ Lev Semionovich Vygostsky. São Paulo: Ática, 2009. 135 p.

ZUIN, Vânia Gomes; ZUIN, Antônio Álvaro Soares. O CELULAR NA ESCOLA E O

FIM PEDAGÓGICO. Educ. Soc., Campinas, v. 39, n. 143, p. 419-435, jun. 2018.

Disponível em <http://www.scielo.br/scielo.php?script=sci_arttext\&pid=S010173302018000200419\&lng=pt\&nrm=iso > . Acesso em: 21 de setembro de 2019. 